Infected individuals were identified and isolated early in infection, preventing spread.

Interventions Daily or frequent testing using three NAAT platforms, rapid point-of-care testing, and symptom monitoring.

Main Outcome Measurements COVID-19 infection.

Conclusion Routine RT-PCR testing allowed early detection of infection. Cycle threshold values provided a useful guidepost for understanding results. Confirmatory processing of initial positive values significantly improved PPV. Antigen POC testing was unable to reliably rule out COVID-19 early in infection. Adjudication processes were able to confirm or rule out SARS-CoV-2.

\section{INJURY TRENDS IN MEN'S ENGLISH PROFESSIONAL FOOTBALL: AN 11 YEAR CASE SERIES}

1,2Ben Palmer, ${ }^{2}$ Michael McBride, 'Gareth Jones, 'Lawrence Mayhew. 'Leeds Beckett University, Leeds, UK: ${ }^{2}$ Scunthorpe United Football Club, Scunthorpe, UK

10.1136/bjsports-2021-IOC.379

Background In a recent single season audit of men's English professional football, the incidence of injury was reported as 9.11 injuries/1000 h (Jones et al., 2019). Whilst this provides an up to date estimate of a single season, there is a paucity of research examining the incidence of injury over multiple seasons in English football.

Objective The aim of this study was to examine the injury trends in English professional football over 11 seasons (2007/ 8-2013/14 and 2015/16-2018/19).

Design Retrospective case series.

Setting Professional football players competing in the English Football League.

Participants 363 players from four squads.

Main outcome Data collection procedures followed the guidelines set out in the Union of European Football Associations (UEFA) consensus for all 11 seasons. Injury incidence per $1000 \mathrm{~h}$ was estimated from match and training exposure.

Results There were 907 injuries recorded over 11 years. The overall incidence rate was $6.5 / 1000 \mathrm{~h}(95 \% \mathrm{CI})$. The incidence rate in match play was significantly higher than training (58 vs $2.8 / 1000 \mathrm{~h}, \mathrm{P}<0.001,95 \% \mathrm{CI}$ ). Incidence rates remained stable over 11 years and there was no significant difference for muscle and ligament incidence rates between seasons $(<0.05)$.

The most common site of injury was the thigh, $(27 \%, 242 /$ 907). Muscle strains accounted for 49\% (445/907) of all injuries. The hamstrings were the most frequently injured muscle group, accounting for 17\% (150/907) of all injuries and 34\% $(150 / 445)$ of muscle injuries. There was a significant increase in the number of hamstring injuries occurring during match play across seasons $(\mathrm{P}=0.024,95 \% \mathrm{CI})$. Re-injuries constituted $6 \%(55 / 907)$ of all injuries and caused longer absences than initial injury (14.7 vs $8.5, \mathrm{P}<0.001,95 \% \mathrm{CI})$.

Conclusions Whilst overall incidence rates remain stable, the incidence of hamstring injuries remains high and re-injuries had a higher severity than initial injuries.
416 ASSESSING THE RISK OF SARS-COV-2 TRANSMISSION IN INTERNATIONAL PROFESSIONAL GOLF

1,2 Patrick Robinson, ${ }^{1,6,7,8}$ Andrew Murray, ${ }^{3}$ Graeme Close, ${ }^{4,5}$ Denis Kinane. ${ }^{1}$ European Tour Performance Institute, Virginia Water, UK; ${ }^{2}$ Edinburgh Orthopaedics, Royal Infirmary of Edinburgh, Edinburgh, UK; ${ }^{3}$ Research Institute for Sport and Exercise Sciences, Liverpool John Moores University, Liverpool, UK; ${ }^{4}$ School of Dental Medicine, University of Berne, Berne, UK; ${ }^{5}$ Medical and Scientific Department, Cignpost Diagnostics, Farnborough, UK; ${ }^{6}$ Sport and Exercise, University of Edinburgh, Edinburgh, UK; ${ }^{7}$ Medical and Scientific Department. The International Golf Federation., Lausanne, UK; ${ }^{8}$ Medical and Scientific Department. The RandA., St. Andrews, UK

\subsection{6/bjsports-2021-IOC.380}

Background There is no published data on the incidence or risk of SARS-CoV-2 virus transmission when playing golf, a sport played outdoors where social distancing is possible.

Objective The purpose of this prospective study was to report incidence and transmission regarding SARS-CoV-2, of professional golfers competing on the PGA European Tour across 23 events in 11 countries.

Design Prospective cohort study

Setting PGA European Tour events

Patients (or Participants) Professional golfers participating on the PGA European Tour

Interventions (or Assessment of Risk Factors) Daily symptom and temperature checks, and weekly Reverse Transcriptase Polymerase Chain Reaction (RT-PCR) screening were performed to determine potential carriage of SARS-CoV-2.

Main Outcome Measurements Onset and type of symptomology were analysed. Gene expression and Cycle Thresholds were reviewed for all positive cases. Repeat PCR testing was performed on all positive players. RT-PCR analysis included human house-keeping genes, and various RNA genes specific for SARS-CoV-2.

Results During the study period, there were 2900 RT-PCR tests performed on 195 professional golfers competing on the European Tour. Four players tested positive on-site during the study period $(0.14 \%$ of tests; positive results were declared with $\mathrm{Ct}<40$.). Two positive tests were returned as part of routine protocols while two reported a history of close contact with an individual who had tested positive for SARSCoV-2 and were isolated and target tested. All were asymptomatic at time of testing, with three developing symptoms subsequently. None required hospital admission. There was no transmission from player to player.

Conclusions Risk of transmission of SARS-CoV-2 virus can be mitigated by highly accurate RT-PCR testing of participants and by setting up a safe bubble which includes testing players and support staff, as well as all persons coming into contact with them during the course of the tournament for example drivers and hotel staff. This report can also provide reassurance for participants and policy makers regarding community golf, which can be encouraged for the health benefits it provides, in a relatively low risk environment, with minimal risk of transmission by observing sensible viral hygiene protocols. 